\title{
ANÁliSE DE AVALIAÇÕES PEDAGÓgICAS PROPOSTAS PARA ALUNOS SURDOS EM CONTEXTO EDUCACIONAL INCLUSIVO BILÍNGUE
}

\author{
Denise Marina RAMOS ${ }^{1}$ \\ Cristina Broglia Feitosa de LACERDA ${ }^{2}$
}

Resumo: Esse estudo objetivou analisar o processo de elaboração e implementação de avaliações pedagógicas pensadas para alunos surdos em contexto de educação inclusiva bilíngue e identificar as estratégias e os recursos didáticos empregados por professores ouvintes bilíngues, do ensino fundamental I, com o intuito de desenvolver avaliações pedagógicas condizentes com as especificidades desses alunos. Constituiu-se em uma investigação de caráter exploratório e de abordagem qualitativa. $\mathrm{O}$ processo de coleta de dados compreendeu a realização de entrevistas semiestruturadas com professores ouvintes bilíngues, bem como análise documental, utilizando-se como fonte as avaliações de conteúdos pedagógicos desenvolvidas e propostas por esses profissionais para os alunos surdos. Os dados obtidos foram analisados com base em eixos de análise que emergiram dos próprios dados. Pode-se dizer que as professoras participantes desse estudo avaliam o aluno surdo a partir de pressupostos e metodologias que reconhecem as suas especificidades linguísticas e culturais.

Palavras-chave: Educação dos surdos. Educação bilíngue. Avaliação pedagógica.

\section{Introdução}

O presente estudo tem como objetivo analisar o processo de elaboração e implementação de avaliações pedagógicas pensadas para alunos surdos em contexto de educação inclusiva bilíngue, e identificar as estratégias e os recursos didáticos empregados por professores ouvintes bilíngues com o intuito de desenvolver avaliações condizentes com as especificidades do aluno surdo. $\mathrm{O}$ contexto analisado refere-se especialmente a uma sala de aula multisseriada do ensino fundamental I, ciclo I e ciclo II, composta por alunos surdos e dois professores ouvintes bilíngues, de uma escola municipal de ensino fundamental de um município de médio porte do estado de São Paulo, onde se desenvolve uma Programa Inclusivo Bilíngue. Nesse sentido, o estudo

\footnotetext{
${ }^{1}$ Doutoranda em Educação Especial. UFSCar - Universidade Federal de São Carlos. Centro de Educação e Ciências Humanas - Pós-graduação em Educação Especial. São Carlos - SP - Brasil. 13565-905 denise.m.ramos1@gmail.com

2 Pesquisadora do projeto em rede “Acessibilidade no Ensino Superior” (Obeduc/Capes). UFSCar Universidade Federal de São Carlos. Centro de Educação e Ciências Humanas - Pós-Graduação em Educação Especial. São Carlos - São Paulo - Brasil. 13565-905 - clacerda@ufscar.br
} 
proposto está articulado a um projeto de pesquisa ${ }^{3}$ que tem realizado ações de acompanhamento e investigação no âmbito de um Programa Inclusivo Bilíngue para surdos, o qual tem como princípio o desenvolvimento de uma educação bilíngue para alunos surdos e, por essa razão, incorpora a Língua Brasileira de Sinais (Libras) ao ambiente escolar e busca efetivar metodologias e práticas didáticas apropriadas aos alunos surdos incluídos. O Programa Inclusivo Bilíngue justifica-se, dentre outros fatores, pela necessidade de se desenvolver uma série de reflexões no interior da escola pública visando transformar seu modo de atender e atuar com sujeitos surdos (LACERDA, 2012).

Conforme a política educacional vigente, a educação de alunos surdos orienta-se segundo uma perspectiva inclusiva, de acordo com princípios de educação bilíngue, assim como promulgado pela Lei n. 10.436 de 2002 (BRASIL, 2002) e pelo Decreto n. 5.626 de 2005 (BRASIL, 2005). Em suma, a proposta educacional bilíngue busca contemplar o direito linguístico do surdo de ter acesso aos conhecimentos sociais e culturais em uma língua acessível a ele, e que ele tenha domínio, assim reconhece a língua de sinais como natural e primeira língua do surdo e assume o aprendizado da língua portuguesa escrita como segunda língua. Ademais, como assinala Skliar (1999, 1997), a educação bilíngue, definida como um reconhecimento político da surdez como diferença ${ }^{4}$, demanda algo além do domínio de duas línguas, aspectos sociais, culturais, curriculares e metodológicos inerentes à condição de surdez também necessitam ser considerados.

Contudo, a despeito da garantia legal, Lacerda (2012, p.10) evidencia que:

[...] a efetivação de propostas educacionais bilíngues ocorre isoladamente, muitas vezes de forma experimental, o que impossibilita que a maioria dos sujeitos surdos possa desfrutar dessa possibilidade de ensino. Como consequência, em nosso país, a maioria dos surdos não tem podido ter acesso a uma escolarização que atente para suas necessidades linguísticas, sociais e culturais, desenvolvida a partir de metodologias de ensino pensadas para esta população [...].

Nesse sentido, em sua maioria, os alunos surdos frequentam escolas em que os processos de ensino e aprendizagem não consideram suas especificidades linguísticas e

${ }^{3}$ O referido projeto conta com o apoio da Fundação de Amparo à Pesquisa do Estado de São Paulo (Fapesp Proc. 12/17730-9).

${ }^{4}$ Conceber a surdez sob uma dimensão política implica em considerá-la como construção histórica, cultural e social, efeito de relações de saber e poder que permeiam as representações, e por sua vez, os discursos e as práticas sobre os surdos e a surdez. 
culturais, pautando-se em padrões socioculturais ouvintes. A esse respeito, Fernandes (1999) assinala que os surdos buscam na escolarização a expectativa de inserção social e conquista de direitos e cidadania, no entanto incorporar-se à escola pode significar privar-se de certos aspectos de sua identidade e cultura, assimilando formas da cultura dominante. Por essa razão, Dorziat (2004) demonstra que a inclusão escolar de alunos surdos, objetivando sua participação social efetiva, demanda uma organização das escolas considerando sobretudo os seguintes critérios: a Libras como língua de instrução e de interação, a valorização de conteúdos escolares e a relação entre conteúdo e cultura surda.

Vale ressaltar que a realidade a ser investigada no presente estudo remete a um programa de escolarização que assume a condição bilíngue do aluno surdo, procurando atuar de modo adequado às suas especificidades linguísticas e distinguindo-se também no tocante à metodologia adotada. Desse modo, a fim de contribuir para as ações relativas ao desenvolvimento do Programa Inclusivo Bilíngue, bem como para as discussões empreendidas no campo, considera-se pertinente examinar o processo de avaliação de alunos surdos nesse contexto, uma vez que constatou-se uma carência de estudos que investiguem essa temática.

Ao discutir sobre os processos de avaliação no campo da Educação Especial e da educação de alunos surdos, Sá (2009) tece críticas aos modelos tradicionais de avaliação, de caráter estático, normatizador e psicométrico, os quais conduzem a práticas sentenciosas, classificatórias, comparativas e reducionistas. Por sua vez, com base nas contribuições de Feuerstein (1979) e Vygotsky (1989), a autora aponta que a avaliação adquire um sentido positivo ao centrar-se no potencial de aprendizagem do educando, oferecendo informações qualitativas para uma intervenção apropriada. Especificamente no caso dos alunos surdos, Sá (2009) adverte que a prática avaliativa deve considerar as questões implicadas em sua educação, assim como os aspectos linguísticos, culturais, curriculares e de identidade. De acordo com a autora,

Na questão da avaliação, o importante é que sejam enfatizadas as potencialidades do educando, e, para que o aluno e a comunidade surda sejam intermediados num processo avaliativo e pedagógico eficientes, faz-se necessário que os educadores tenham uma visão adequada do fazer, do saber, do conviver e do ser surdo. É necessário escapar do imperativo dominante segundo o qual os surdos têm que falar e ser como os outros (ouvintes), mas recorrer a modelos sócioantropológicos nos quais a comunidade de iguais e a língua de sinais exerçam papel fundamental. (SÁ, 2009, p. 9). 
No âmbito dessa discussão, Lunardi-Lazzarin e Camillo (2008, p. 6) examinam a avaliação no contexto da educação de surdos a partir dos discursos produzidos por professores surdos. Segundo as autoras, a avaliação deve ser problematizada a partir das relações de saber e poder que permeiam esse processo. Nessa perspectiva, a avaliação é concebida como um dispositivo pedagógico inventado para narrar e classificar o aluno em certo espaço e tempo. "Essas construções discursivas merecem cuidado quando se reduzem a simples constatações, reforçando condutas inadequadas, pontuando 'faltas' e, assim, delimitando lugares a serem ocupados pelos sujeitos nos espaços escolares e sociais a fim de poder melhor corrigi-los e governá-los."

De acordo com as autoras, em virtude das diversidades presentes nos espaços escolares, a avaliação demanda um olhar flexível e questionador, a partir do reconhecimento do "outro", de suas necessidades e especificidades. Especialmente no contexto da educação de surdos, a avaliação deve fundamentar-se nas diferenças linguísticas e culturais das comunidades surdas e não mais em referenciais ouvintes ou em simples adaptações dentro de modelos socioculturais ouvintes. Portanto,

A pretensão de avaliar a partir do respeito às diferenças não passa pelo princípio da igualdade de educação que costumamos observar, em que todos são avaliados da mesma forma e com os mesmos critérios, formalizando esse processo escolar como meio de normalizar e padronizar os corpos como dóceis, úteis, reguláveis e previsíveis. Nesse contexto, cada aluno é um estudo de caso particular, específico, que merece contínua e intensa observação e registro. (LUNARDILAZZARIN; CAMILLO, 2008, p. 8).

A avaliação é parte do fazer escolar, logo, em um processo avaliativo que sugere reconhecer a diferença surda, bem como os aspectos que envolvem a construção do conhecimento por alunos surdos, as avaliações necessitam ser organizadas considerando-se, sobretudo, a língua de sinais, a visualidade do sujeito surdo e a sua dificuldade em acessar o Português como segunda língua.

A esse respeito, Fernandes ([2014]) assinala que o ensino e a aprendizagem de alunos surdos requer uma modalidade linguística que considere a sua experiência visual, desse modo, o acesso precoce à Libras possibilita suprir as lacunas que a oralidade não contempla no desenvolvimento da linguagem e compreensão do mundo. Adquirida a língua de sinais, ela terá papel fundamental no aprendizado do Português, na modalidade escrita, como segunda língua. Contudo, segundo a autora, a possibilidade do aprendizado da escrita requer professores capacitados e metodologias específicas, a 
partir de estratégias visuais, baseadas na língua de sinais e semelhantes aos métodos empregados no ensino de línguas estrangeiras para ouvintes.

Destarte, considerando-se os apontamentos prévios, as seguintes questões nortearam o presente estudo: de que modo são constituídas e efetivadas avaliações pedagógicas propostas para alunos surdos em contexto educacional inclusivo bilíngue? Quais estratégias e recursos didáticos possibilitam desenvolver avaliações pedagógicas adequadas às especificidades do aluno surdo?

\section{Método}

Esse estudo constituiu-se em uma investigação de caráter exploratório e de abordagem qualitativa (VILELAS, 2009). Foi aprovado pelo Comitê de Ética em Pesquisa (CAAE: 19840013.4.0000.5504), bem como foram contemplados os aspectos éticos para sua realização, conforme a Resolução do Conselho Nacional de Saúde n. 466 de 2012 (BRASIL, 2012).

Para a coleta de dados foram realizadas entrevistas semiestruturadas (MANZINI, 2004) com dois professores ouvintes bilíngues regentes de uma classe bilíngue multisseriada, no contexto de uma escola municipal de ensino fundamental de um município de médio porte do estado de São Paulo, onde se desenvolve o Programa Inclusivo Bilíngue para surdos. Por meio das entrevistas buscou-se apreender o processo de elaboração e implementação das avaliações pedagógicas pensadas para os alunos surdos e identificar as estratégias e os recursos didáticos empregados por esses professores com o intuito de desenvolver avaliações condizentes com as especificidades do aluno surdo. As entrevistas foram registradas por meio de gravador digital e posteriormente transcritas na íntegra. As transcrições foram apresentadas aos respectivos professores para análise e concordância do conteúdo transcrito.

Paralelamente, foram analisadas as avaliações pedagógicas desenvolvidas e propostas por esses professores aos alunos surdos no sentido de complementar as informações obtidas por meio das entrevistas, nesse sentido, foram observados aspectos referentes à elaboração, constituição e efetivação desse instrumento avaliativo. Os resultados das avaliações não foram considerados e analisados no presente estudo.

Os dados obtidos por meio das entrevistas semiestruturadas e análise das avaliações pedagógicas foram examinados segundo eixos de análise que emergiram a partir dos dados coletados. 


\section{Resultados e discussão}

Os resultados serão apresentados e discutidos segundo os eixos de análise: "A prática docente em uma perspectiva educacional inclusiva bilíngue", "Elaboração e constituição das avaliações pedagógicas" e "Efetivação do processo avaliativo", os quais emergiram a partir dos dados coletados.

Destaca-se que as professoras ouvintes bilíngues atuam em conjunto em uma sala de aula bilíngue multisseriada, formada por alunos surdos que se encontram em diferentes anos do ensino fundamental I, ciclo I e ciclo II, cuja língua de instrução e de interação é a Libras. Vale ressaltar que durante a aplicação das avaliações toda a instrução referente aos exercícios propostos é dada em Libras.

\section{A prática docente em uma perspectiva educacional inclusiva bilíngue}

Neste tópico são apresentados aspectos sobre a prática docente em uma perspectiva educacional inclusiva bilíngue, segundo as concepções e apontamentos das professoras participantes desse estudo.

De acordo com os relatos das professoras, a prática docente apresenta-se como um desafio, sobretudo em virtude do pouco conhecimento sobre a surdez e de suas implicações educacionais, evidenciando as fragilidades da formação inicial, bem como a necessidade e a relevância da formação continuada em serviço. Assinala-se também, a carência de modelos educacionais bilíngues no sentido de fomentar reflexões e elucidar parâmetros para uma prática docente mais efetiva conforme essa perspectiva. Ainda, segundo os apontamentos das professoras, a abordagem educacional bilíngue desvela-se como uma proposta rica e determinante para o desenvolvimento e escolarização dos alunos surdos, em especial no que concerne à aquisição da linguagem. O relato a seguir possibilita ilustrar tais considerações.

É um desafio, porque eu não tinha uma formação específica para a questão de trabalhar com crianças surdas, então o que eu tive foi uma formação pedagógica, da Pedagogia, e a Libras, é isso o que eu tive quando comecei aqui. E o que me ajuda, e acredito que os outros que trabalham aqui também, são as formações que a gente tem com toda equipe, os estudos que a gente faz, pois as disciplinas que a gente acaba vendo na faculdade sobre alunos com deficiências são bem curtas, um semestre, às vezes bem menos que isso. Aqui na escola é uma proposta muito rica e que exige de nós professores um comprometimento grande, estudo, porque não é fácil, nós não temos outros modelos de escola bilíngue para olhar, para comparar, para saber se está no caminho certo, então o nosso trabalho é mesmo um 
desafio e é uma tentativa e erro, é um pensar, um repensar constante sobre a prática. (Relato do professor).

Nota-se o desejo de serem contemplados nos cursos de formação inicial e continuada de professores conhecimentos para atuar na educação de surdos, como questões linguísticas e culturais relativas à surdez, aspecto igualmente observado no estudo desenvolvido por Lunardi-Lazzarin e Camillo (2008).

Mahl e Ribas (2013), em estudo realizado sobre a avaliação escolar de alunos surdos, também constataram que a maior parte dos professores entrevistados apontou a formação e a capacitação docente, assim como o conhecimento e o aprendizado da Libras, como fatores primordiais para uma atuação mais efetiva com alunos surdos incluídos em escolas regulares.

Contudo, sublinha-se para a necessidade dos conteúdos dos cursos e programas de formação de professores reorientarem-se no sentido de superar uma lógica da deficiência, pautada em representações e discursos que mascaram a questão política da diferença (SKLIAR, 2014). Nesse sentido, Skliar (2014, p. 7) ressalta que no âmbito da formação é preciso considerar quatro questões fundamentais: "O que se deve ensinar (uma questão sobre cultura)? Porque (uma questão de cidadania)? A quem (consideração do outro)? Como (comunicabilidade do saber)?”

Por fim, como indicado no relato da professora participante desse estudo, evidencia-se a pertinência da formação continuada em serviço, centrada na prática e no professor, configurando-se em um espaço permanente para o desenvolvimento de estudos, reflexão, orientação e discussão de temas de interesse da equipe, bem como de socialização de dúvidas e angústias e de trocas significativas entre os pares, a fim de buscar caminhos para melhor atender as necessidades dos alunos.

\section{Elaboração e constituição das avaliações pedagógicas}

Neste tópico apresentam-se elementos acerca do processo de elaboração e constituição das avaliações pedagógicas pensadas para os alunos surdos, assim como as estratégias e os recursos didáticos empregados no desenvolvimento desse instrumento avaliativo.

Por se tratar de uma sala de aula multisseriada, as avaliações pedagógicas passam por adaptações e adequações curriculares de acordo com o ano em que cada aluno se encontra e especialmente, conforme as necessidades educacionais de cada aluno. 
As avaliações nós preparamos quase que individualmente, porque no meu caso é quarto e quinto, então em uma avaliação de matemática são duas avaliações de matemática, para o quarto ano e para o quinto ano, então é preciso pensar muito no aluno para elaborar essa prova, eu não posso copiar e colar qualquer exercício, então eu acho que o professor tem que ter em mente para quem é essa avaliação, qual o objetivo dessa avaliação e porque também que eu vou fazer essa avaliação. (Relato do professor).

A figura 1 apresenta um exercício extraído da avaliação de língua portuguesa do $3^{\circ}$ bimestre, em seguida, as figuras 2 e 3 apresentam as adaptações realizadas em razão das singularidades e necessidades dos alunos surdos.

Figura 1 - Exercício de leitura, interpretação e escrita.

3) Complete a história com as palavras que faltam. Tenha muita atenção!

ERA UMA VEZ TRES Yforqumnhor QUE ERAM IRMÃOS E QUE CERTO DIA DECIDIRAM CONSTRUIR SUAAS PRÓPRIAS Caree.

O PRIMEIRO PORQUINHO TEVE ENTÃO A IDEIA DE CONSTRUIR UMA com alh $x$ DE maderod. SERIA MUITO BONITA E NÃO DARIA MUITO lemptrabelwo O QUE ERA ÓTIMO, POIS ELE ERA BEM quígrigaro, NÃO
GOSTAVA MUITO DE TRABALHAR.

OS OUTROS DOIS PORQUINHOS CONTINUARAM A ANDAR E LOGO VIRAM UM HOMEM CORTANDO LENHA. O SEGUNDO PORQUINHO TEVE A DEIA DE CONSTRUIR UMA BELA CASA DE Imadeleci-SERIA RESISTENTE E FACIL DE MONTAR.

O ÚLTIMO PORQUINHO ERA DETALHISTA E TRABALHADOR. SENDO ASSIM, ELE NÃO TINHA FICADO SATISFEITO COM OS MATERIAIS ESCOLHIDOS POR SEUS IRMÃOS.

ENQUANTO ELE CAMINHAVA, VIU UM HOMEM ARRUMANDO UM MURO DE TIJOLOS E ACHOU QUE AQUELE SERIA UM EXCELENTE MATERIAL PARA CONSTRUIR SUA thelora ELE PODERIA FAZER UMA CASA RESISTENTE E CONFORTAVEL.

DEPOIS DE ALGUNS DIAS, UM lol MMAU PASSOU POR ALI. ELF

ESTAVA COM FOME E SENTIU O CHEIRO DOS PORQUINHOS.

BATEU NA PORTA DA CASA DE Palha E DISSE:

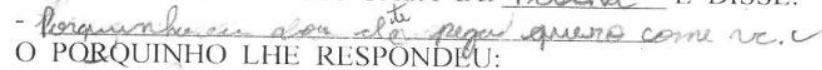

- nera.

Fonte: Avaliação de conteúdos pedagógicos. 
Figura 2 - Adaptação mediante exercício de leitura com uso de recursos visuais.

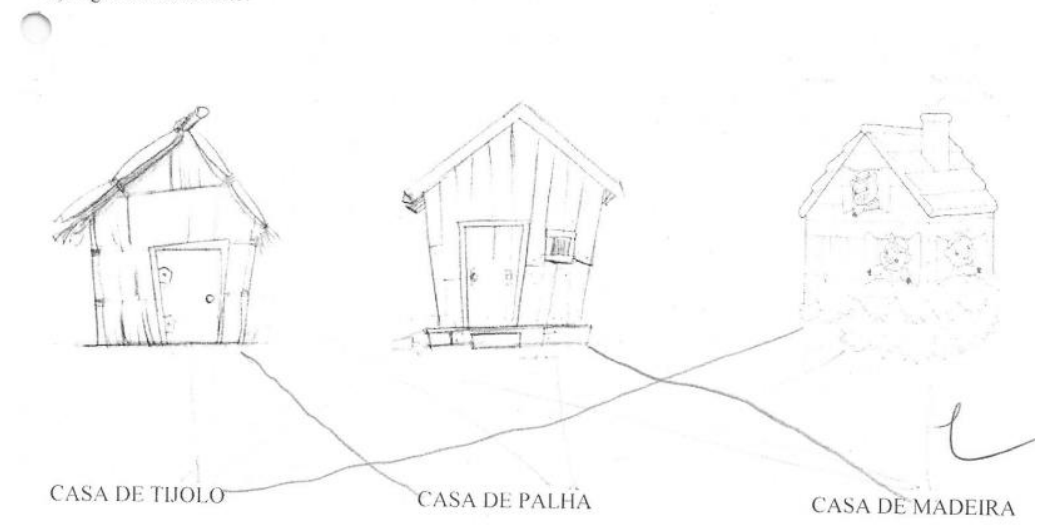

Fonte: Avaliação de conteúdos pedagógicos.

Figura 3 - Adaptação mediante exercício de leitura, ordenação e reescrita com apoio visual.

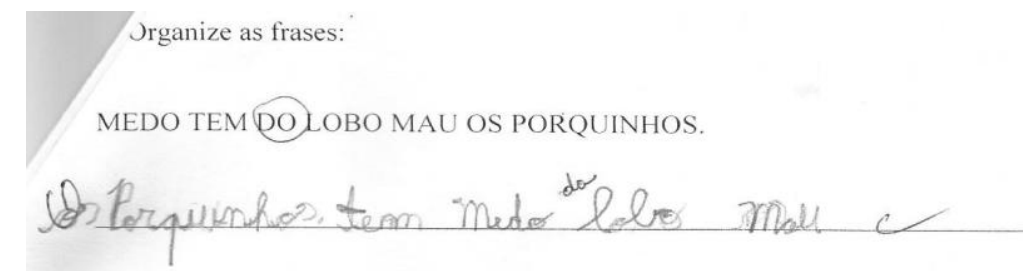

O CASA DE PALHA. LOBO ASSOPROU A

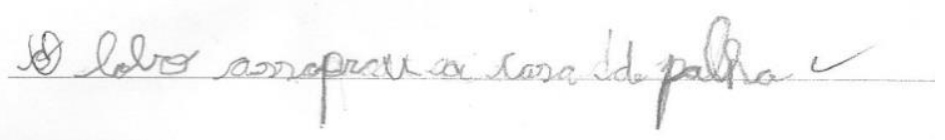

O CASA DE MADEIRA. LOBO ASSOPROU A

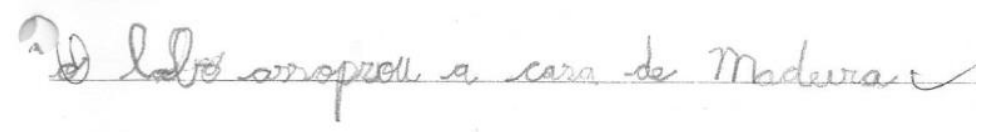

CAIU NÃO. A CASA DE TIJOLO

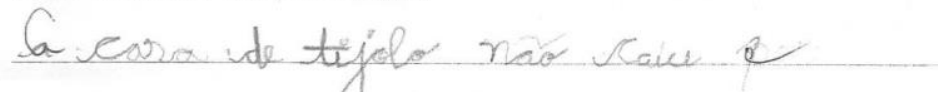

Fonte: Avaliação de conteúdos pedagógicos.

A seguir, as figuras 4 e 5 apresentam exercícios que envolvem sequenciação das cenas da história, interpretação e escrita do texto. Essa proposta também foi adaptada, em virtude das especificidades de alguns alunos, focalizando somente a atividade de interpretação e ordenação da história, assim como na figura 4. 
Figura 4 - Exercício de interpretação e sequenciação da história.

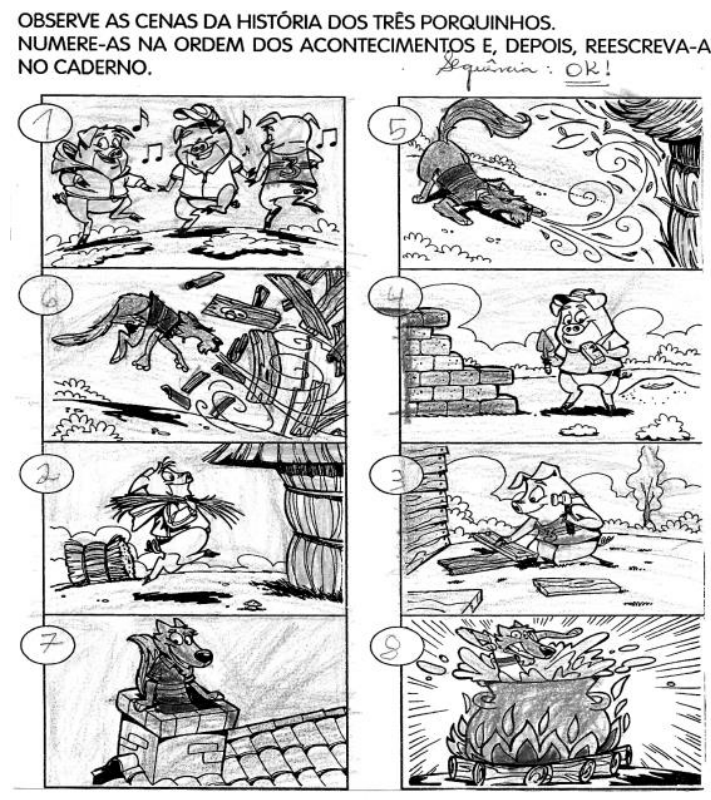

Fonte: Avaliação de conteúdos pedagógicos.

Figura 5 - Exercício de interpretação e escrita.

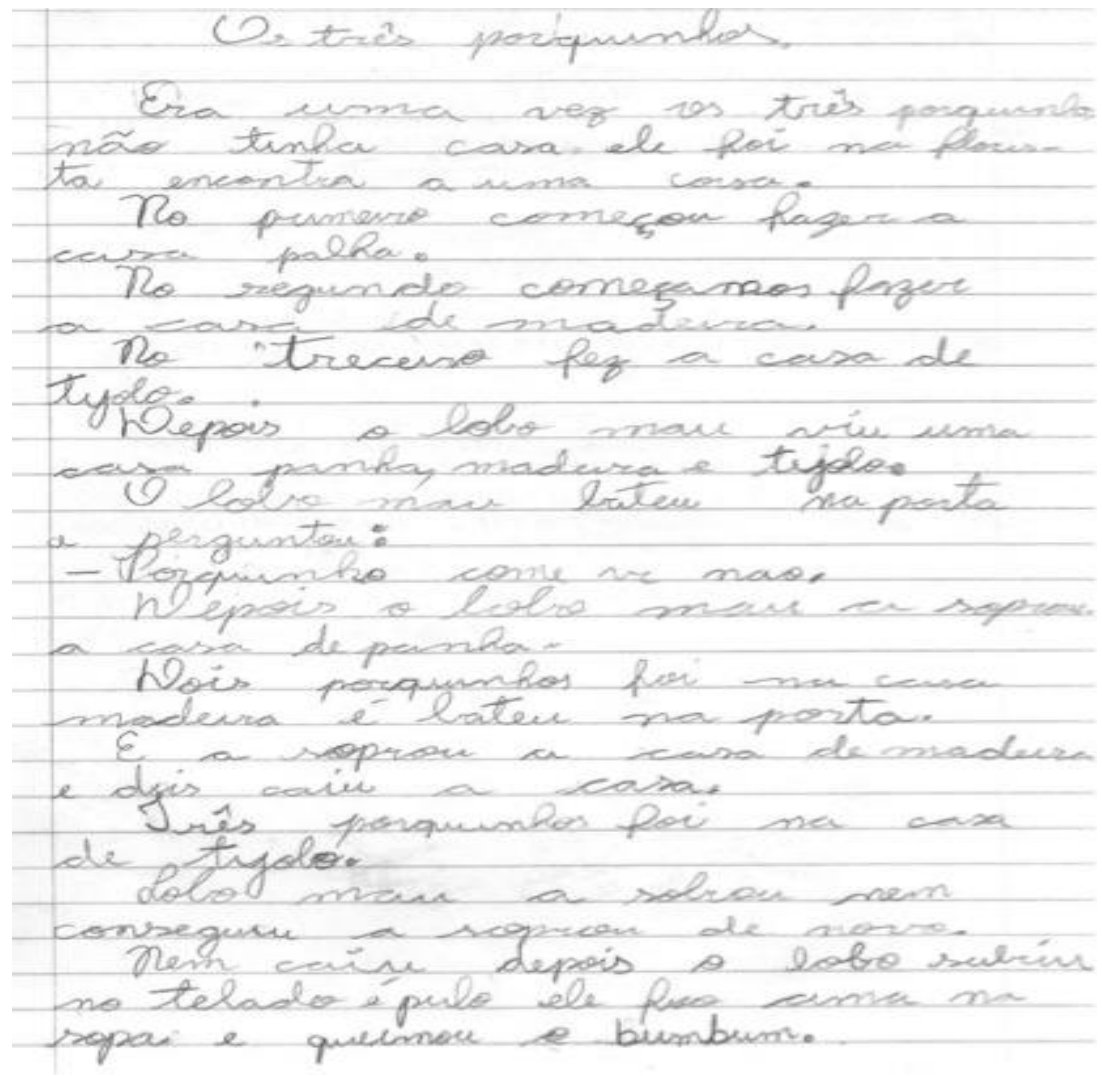

Fonte: Avaliação de conteúdos pedagógicos. 
Ressalta-se que os exercícios apresentados e as adaptações e adequações realizadas foram dirigidos a diferentes alunos, considerando-se a trajetória de cada aluno, as habilidades e dificuldades observadas e o ciclo/ano em que se encontra. Desse modo, pode-se observar que os referidos exercícios apresentam finalidades similares, assim como avaliar a aquisição e o desenvolvimento de habilidades de leitura, escrita e interpretação, adequando-se contudo, às especificidades de cada aluno. Os exercícios propostos partem de um tema e objetivos comuns, mas são explorados de diferentes formas, requerendo diferentes estratégias para a realização dos mesmos.

Em especial no que concerne à avaliação das produções escritas dos alunos surdos, observou-se que os exercícios propostos privilegiam a leitura e a dimensão visual da escrita no processo de interpretação e produção textual, além disso, pode-se afirmar, conforme o relato a seguir, que as professoras adotam critérios diferenciados de avaliação e demonstram reconhecer as especificidades linguísticas de um processo de aprendizagem de segunda língua.

A gente sempre tenta priorizar a questão visual, porque esse é um sentido neles que é bem aguçado, então nós priorizamos uma avaliação que tenha mais leitura do que escrita, pelo menos nesse momento que eles estão passando por uma etapa de letramento, então mesmo em uma prova de Português, ao invés de eu pedir para que eles escrevam palavras que eles conhecem daquele tema, a gente dáo texto e eles podem pintar no texto aquela palavra, dá mais segurança para os alunos, mostra o que eles aprenderam e acaba não sendo cruel para eles, porque o Português ainda é mais complicado nesse processo de escolarização. (Relato do professor).

Desse modo, compreende-se, como ratifica Gesueli (1998, p. 134), que "O apoio na dimensão visual na significação da escrita parece muito relevante neste processo de construção, principalmente pelo fato de que as crianças têm uma experiência visual intensa e não ouvem." Além disso, a autora destaca a importância da língua de sinais nesse processo no sentido de subsidiar a leitura e a compreensão do Português escrito, mediante um trabalho interpretativo partindo dos sinais para chegar à escrita.

Para Fernandes ([2014]), considerando-se as especificidades linguísticas desse processo de aprendizagem de segunda língua, a avaliação das produções escritas de alunos surdos necessita reconhecer as peculiaridades e dificuldades inerentes a esse processo, seja pela interposição da língua de sinais nas hipóteses de escrita do Português, seja por falta de explicações e recursos apropriados nas metodologias de ensino empregadas. Assim, 
O foco da avaliação da escrita dos surdos deverá valorizar o conteúdo, suas tentativas de produzir significados na escrita, mesmo que as palavras sejam inadequadas e nem sempre redigidas da maneira convencional. Em relação à forma ou estrutura do texto, [...] é fundamental que sejam utilizados critérios diferenciados de avaliação em relação aos possíveis "erros" apresentados. (FERNANDES, [2014], p. 19).

No âmbito dessas considerações, Laplane e Silva (2012) assinalam para a

necessidade de o professor conhecer o processo de aquisição e desenvolvimento da escrita de alunos surdos, considerando suas produções como resultados de um processo particular e como indicadores de aprendizagens futuras.

Acerca do emprego de recursos visuais, notou-se que as avaliações apresentam um número significativo de imagens, como figuras e gráficos, especialmente nas avaliações referentes às disciplinas de Matemática, Ciências, História e Geografia. Essas avaliações possibilitam também, o uso do desenho como recurso para os alunos surdos responderem às questões. As figuras 6 e 7 elucidam esses dados, bem como os relatos que seguem.

A prova dos alunos tem muito desenho, tem muita figura, ela tem vários esquemas. Nós também recorremos bastante a questões de múltipla escolha, especialmente em provas de Geografia, por exemplo, quando vai trabalhar a questão dos estados, a gente coloca um mapa, tem os estados e é preciso nomear, então a gente coloca alternativas, as questões de múltipla escolha que é também uma estratégia de leitura para eles, então a cada bimestre a gente vai aprofundando mais nessa questão, vai tirando esses apoios e exigindo um pouquinho mais gradualmente. (Relato do professor).

Figura 6 - Exercício de contagem com recursos visuais.
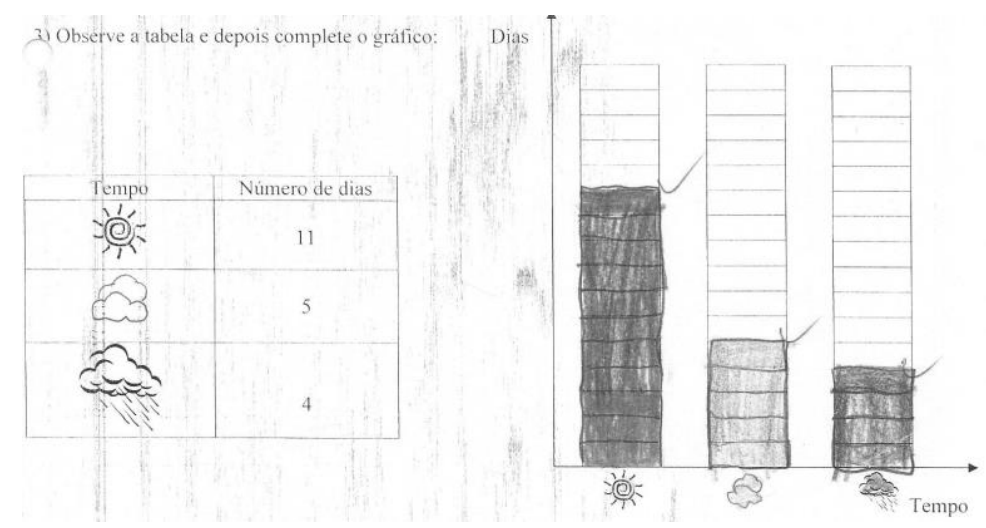

Fonte: Avaliação de conteúdos pedagógicos. 
Figura 7 - Desenhos como meio para a resolução de exercício.

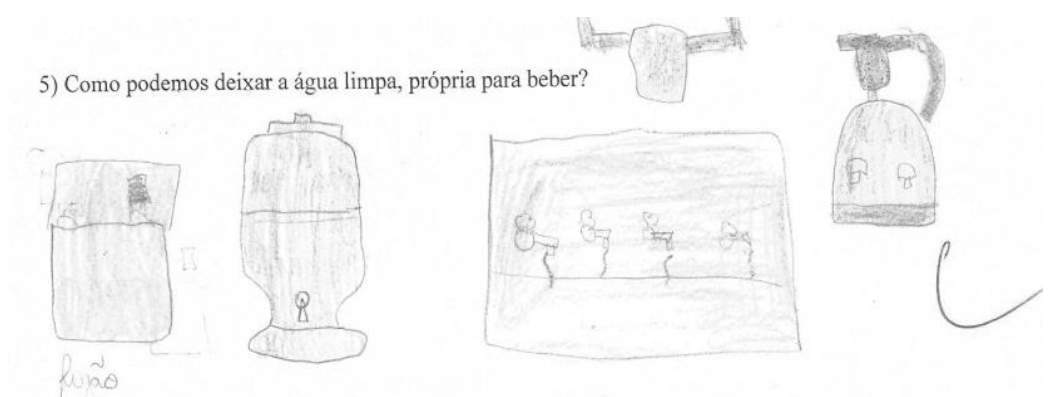

Fonte: Avaliação de conteúdos pedagógicos.

Evidencia-se, portanto, a importância da utilização de recursos visuais para a construção de sentidos e significados pela criança surda. A esse respeito, Reily (2003, p.161) afirma que "Crianças surdas em contato inicial com a Língua de Sinais necessitam de referências da linguagem visual com as quais tenham possibilidade de interagir, para conseguirem construir significados." De acordo com a autora, diferentes sistemas semióticos, assim como as linguagens orais ou escritas, as linguagens do corpo e linguagens visuais, podem exercer funções similares para a construção e apropriação de sentidos pelo homem. No caso da criança surda, a linguagem visual constitui-se em um elemento fundamental ao significar sua experiência no mundo, já que a significação não poderá ser processada por vias que dependam da audição.

Nesse sentido, Campello (2008) afirma que o respeito ao processamento cognitivo da visualidade, a qual se estrutura fundamentalmente com signos imagéticos, configura-se como condição essencial para a escolarização de crianças surdas. A autora enfatiza, portanto, a importância de se desenvolver práticas educativas pautadas no signo visual.

Sobre a possibilidade dos alunos surdos utilizarem o desenho como um recurso para a resolução dos exercícios propostos, pode-se dizer que dada a sua especificidade linguística, bem como sua leitura e compreensão de mundo centrar-se em uma dimensão visual, é preciso reconhecer os diferentes elementos das produções textuais de estudantes surdos, pautados também na imagem e nos possíveis desenhos como repletos de significado e representativos da escrita (GESUELI, 2004).

Verificou-se ainda, que em muitos exercícios os enunciados e textos continham os nomes dos colegas de classe ou professoras e experiências vivenciadas pela turma, a fim de torná-los mais significativos aos alunos e de auxiliá-los na construção de 
sentidos em circulação nos textos. O aluno surdo não fala a língua que precisa aprender a ler e a escrever e por isso demanda algum léxico familiar para enfrentar o desafio da leitura, e as professoras demonstram compreender isso. A figura 8 ilustra esses dados, contudo vale ressaltar que os nomes dos alunos e professoras foram omitidos a fim de garantir o sigilo sobre a identidade dos participantes desse estudo.

Figura 8 - Leitura, interpretação e escrita com experiências vivenciadas pela turma.

ATIVIDADES DE SÁBADO E DOMIVGo

OS ALUNOS DA SALA BILINGUU FIZERAM VÁRIAS COISAS LEGAIS NO FNAL. DE SEMANA.
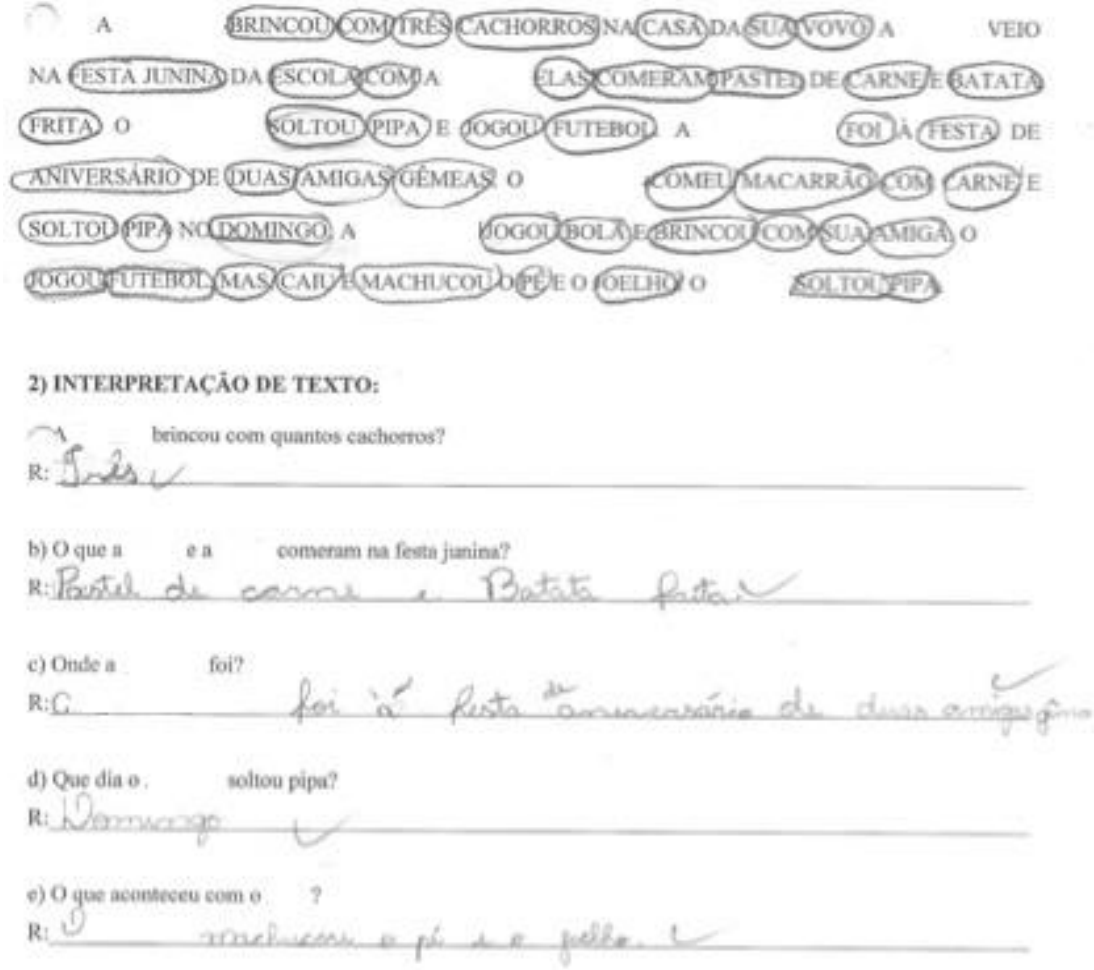

Fonte: Avaliação de conteúdos pedagógicos.

Considerando-se o exposto até o momento, é oportuno retomar algumas considerações de Lunardi-Lazzarin e Camillo (2008) acerca da avaliação no campo da educação de surdos.

Para o aluno surdo, por exemplo, é preciso entender que a experiência educacional, antes de tudo, é visual. Portanto, entender a avaliação a partir da especificidade surda é oferecer estratégias, métodos, recursos e práticas que contemplem sua língua natural - língua de sinais - e sua forma de expressão nos instrumentos e espaços avaliativos. (LUNARDI-LAZZARIN; CAMILLO, 2008, p. 7). 
As avaliações são tradicionalmente um registro escrito do conhecimento, o qual se configura como a forma de aferição mais utilizada. No entanto, no contexto observado as instruções são mediadas pela língua de sinais, o material escrito é mantido, contudo acrescido de imagens e desenhos, ou seja, há um apelo imagético no material e se aceita também respostas que privilegiem a imagem. Nota-se, portanto, dois modos de adaptação: busca-se fazer uma avaliação tangível no que se refere ao conhecimento e também no que se refere à apreensão do Português mediado por imagens.

\section{Efetivação do processo avaliativo}

Neste tópico apresentam-se alguns dados referentes à implementação e efetivação do processo avaliativo, suscitando questões acerca das concepções das professoras participantes desse estudo sobre a prática da avaliação.

As avaliações são realizadas bimestralmente para as disciplinas de Língua Portuguesa, Matemática, Ciências, Geografia e História. No que tange à correção das avaliações, as professoras inserem comentários ao longo das provas, mas não incluem as notas atribuídas, a fim de evitar que os alunos façam comparações entre si, bem como porque a atribuição de notas referente a cada bimestre é realizada considerando-se o processo de ensino e aprendizagem como um todo, não focalizando somente os resultados das avaliações efetuadas.

Na correção da avaliação nós não colocamos uma nota, porque nós somos uma sala multisseriada, então os parâmetros são um pouco diferentes para a questão da avaliação, a nossa nota bimestral não é só a nota daquela avaliação que ele fez, é uma nota do percurso que ele teve no bimestre, o desenvolvimento dele. (Relato do professor).

É possível observar que as professoras compreendem a avaliação como um instrumento que possibilita acompanhar o desenvolvimento dos alunos, e como um indicador para a reflexão e o redirecionamento da prática pedagógica.

Na avaliação é para ver o conhecimento do aluno, as dificuldades que ele tem e os avanços, comparar isso de bimestre a bimestre, mas também perceber onde é que a gente como professora também está errando, então a avaliação é tanto para o aluno como para nós professores, a gente sempre pensa assim. (Relato do professor).

Então a nossa tentativa é pensar em uma avaliação que não seja punitiva, mas de mostrar para o aluno, para que ele enxergue 
também, o que ele precisa melhorar e o que ele precisa se debruçar mais nos estudos. (Relato do professor).

Desse modo, ressalta-se o caráter investigativo da prática avaliativa, como parte integrante do processo de ensino e aprendizagem, opondo-se a modelos tradicionais que incidem, sobretudo, na verificação de rendimento e identificação das dificuldades de aprendizagem. Para Camillo (2009, p. 81), “As práticas educacionais e avaliativas devem vislumbrar e proporcionar o desenvolvimento de cada aluno naquilo que ele pode, da maneira que lhe é possível, e não no sentido de massificar, normalizar suas condutas, objetivando uma utópica 'educação igual para todos'.”

Além disso, com base nos dados obtidos por meio dos relatos das professoras e da análise das avaliações pedagógicas, pode-se afirmar que o processo de elaboração, constituição e efetivação desse instrumento avaliativo tem considerado a trajetória e as especificidades do aluno surdo, fundamentando-se em suas diferenças linguísticas e culturais.

\section{Considerações finais}

O presente estudo visou analisar o processo de elaboração e implementação de avaliações pedagógicas pensadas para alunos surdos em contexto de educação inclusiva bilíngue, desse modo, a partir dos instrumentos metodológicos utilizados foi possível observar que as professoras participantes desse estudo avaliam o aluno surdo a partir de pressupostos e metodologias que reconhecem a surdez como diferença, superando um modelo baseado em referenciais ouvintes. Pode-se dizer que no processo de elaboração e implementação desse instrumento avaliativo são consideradas as singularidades linguísticas e culturais dos alunos surdos, configurando-se em um elemento constitutivo do processo de ensino e aprendizagem.

O aluno surdo pode mostrar mais e melhor o que sabe, pois é considerada sua especificidade linguística, as professoras exploram a dimensão visual dos exercícios, bem como são aceitos desenhos ou outros modos de registros para sua resolução, desse modo, o Português não constitui-se um entrave para o aluno expressar o que sabe.

Para o professor, ver como o seu aluno está lendo ou escrevendo é fundamental para orientar suas ações. O ensino do Português como segunda língua é algo defendido, mas como fazer e que efeitos isso tem para os alunos é algo a ser construído na relação pedagógica e a avaliação pode ser um instrumento importante para orientar o professor. 
Destarte, com base nos dados analisados, assinala-se a relevância de se organizar instrumentos avaliativos que considerem a língua de sinais como primeira língua e o aprendizado do Português escrito como segunda língua, como também a visualidade do sujeito surdo e os aspectos relativos ao seu modo de apreender e interpretar o mundo.

Evidencia-se ainda, a necessidade de se contemplar nos cursos e programas de formação docente questões linguísticas, culturais e identitárias dos surdos, bem como, a imprescindibilidade de ações que visem implementar propostas educacionais bilíngues, de modo que represente as experiências da diferença surda.

Por fim, destaca-se a pertinência de estudos que analisem aspectos da prática docente em uma perspectiva educacional inclusiva bilíngue e, em especial, do processo avaliativo de alunos surdos, a fim de lançar luzes para reflexões e ações futuras.

\title{
ANALYSIS OF PEDAGOGICAL EVALUATIONS PROPOSED FOR DEAF STUDENTS ON BILINGUAL INCLUSIVE EDUCATIONAL CONTEXT
}

\begin{abstract}
This study aimed to analyze the process of elaboration and implementation of pedagogical evaluations thought to deaf students in the context of bilingual inclusive education and identify the strategies and teaching resources employed by bilingual listeners teachers, from elementary school, with the purpose of develop pedagogical evaluations that are consistent with the specificities of these students. It consisted in an exploratory research and qualitative approach. The data collection process involved the realization of semi-structured interviews with bilingual listeners teachers, as well as documental analysis, using as source the evaluations of pedagogical contents developed and proposed by these professionals for the deaf students. The data were analyzed based on the analysis axes that emerged from the data itself. It can be said that the teachers in this study evaluate the deaf student from assumptions and methodologies that recognize their language and cultural specificities.
\end{abstract}

Key words: Education of the deaf. Bilingual education. Evaluation.

\section{REFERÊNCIAS}

BRASIL. Ministério da Saúde. Conselho Nacional de Saúde. Comissão Nacional de Ética em Pesquisa. Homologo a Resolução CNS No 466, de 12 de dezembro de 2012, nos termos do Decreto de Delegação de Competência de 12 de novembro de 1991. Resolução CNS 466, de 13 de junho de 2013. Diário Oficial [da] União, Brasília, 13 jun. 2013. Seção 1, p. 59. Disponível em: <http://conselho.saude.gov.br/resolucoes/2012/Reso466.pdf>. Acesso em: 15 jun. 2016. 
BRASIL. Decreto n. 5.626, de 22 de dezembro de 2005. Regulamenta a Lei n. 10.436, de 24 de abril de 2002, que dispõe sobre a Língua Brasileira de Sinais - Libras, e o art. 18 da Lei n. 10.098, de 19 de dezembro de 2000. Diário Oficial [da] União, Brasília, 23 dez. 2005. Disponível em: <http://www.planalto.gov.br/ccivil_03/_ato20042006/2005/decreto/d5626.htm>. Acesso em: 15 jun. 2016.

BRASIL. Lei n. 10.436, de 24 de abril de 2002. Dispõe sobre a Língua Brasileira de Sinais - Libras e dá outras providências. Diário Oficial [da] União, Brasília, 25 abr. 2002. Disponível em: <http://www.planalto.gov.br/ccivil_03/LEIS/2002/L10436.htm>. Acesso em: 15 jun. 2016.

CAMILLO, C. R. M. Avaliação como dispositivo pedagógico: narrativas de professores surdos no contexto das práticas pedagógicas. In: THOMA, A. da S.; KLEIN, M. (Org.). Currículo e avaliação: a diferença surda na escola. Santa Cruz do Sul: Edunisc, 2009. p.69-85.

CAMPELlO, A. R. e S. Aspectos da visualidade na educação de surdos. 2008. Tese (Doutorado em Educação) - Centro de Ciências da Educação, Universidade Federal de Santa Catarina, Santa Catarina, 2008.

DORZIAT, A. Educação de surdos no ensino regular: inclusão ou segregação? Revista do Centro de Educação, Santa Maria, v. 24, p. 1-7, 2004. Disponível em: <http://coralx.ufsm.br/revce/ceesp/2004/02/a8.htm>. Acesso em: 15 jun. 2016.

FERNANDES, S. Avaliação em língua portuguesa para alunos surdos: algumas considerações. [2014]. Disponível em:

<http://www.educadores.diaadia.pr.gov.br/arquivos/File/janeiro2013/otp_artigos/sueli_f ernandes.pdf>. Acesso em: 15 jun. 2016.

FERNANDES, S. É possível ser surdo em Português? língua de sinais e escrita: em busca de uma aproximação. In: SKLIAR, C. (Org.). Atualidade da educação bilíngue para surdos. Porto Alegre: Mediação, 1999. v. 2. p.59-81.

FEUERSTEIN, R. The dynamic assessment of retarded performers: the learning potential assessment device, theory, instruments and techniques. Baltimore: University Park Press, 1979.

GESUELI, Z. M. A escrita como fenômeno visual nas práticas discursivas de alunos surdos. In: LODI, A. C. B.; HARRISON, K. M. P.; CAMPOS, S. R. L. de. (Org.). Leitura e escrita no contexto da diversidade. Porto Alegre: Mediação, 2004. p.39-49.

GESUELI, Z. M. A criança surda e o conhecimento construído na interlocução em língua de sinais. 1998. Tese (Doutorado em Educação) - Faculdade de Educação, Universidade Estadual de Campinas, Campinas, 1998.

LACERDA, C. B. F. de. Educação inclusiva bilíngue: acompanhamento e implicações para ações pedagógicas junto a alunos surdos no Ensino Fundamental. 2012. Projeto de Parceria Secretaria Municipal de Educação de São Carlos-SP e Universidade Federal de São Carlos (UFSCar), 2012. 
LAPLANE, A. L. F.; SILVA, I. R. Dificuldades na aquisição da escrita e avaliação escolar. In: MENDES, E. G.; ALMEIDA, M. A. (Org.). Dimensões pedagógicas nas práticas de inclusão escolar. Marília: ABPEE, 2012. p.215-229.

LUNARDI-LAZZARIN, M. L.; CAMILLO, C. R. M. Tratar de avaliar, tratar de disciplinar: o contex to da avaliação na educação de surdos. 2008. Trabalho apresentado à $31^{a}$ Reunião Anual da Anped, Caxambu, 2008. Disponível em:

<http://31 reuniao.anped.org.br/1trabalho/GT15-4772--Int.pdf>. Acesso em: 15 jun. 2016.

MAHL, E.; RIBAS, V. A. Avaliação escolar para alunos surdos: entendimentos dos professores sobre este processo. In: CONGRESSO BRASILEIRO

MULTIDISCIPLINAR DE EDUCAÇÃO ESPECIAL, 7.; Encontro da Associação Brasileira de Pesquisadores em Educação Especial, 8., 2013, Londrina. Anais... Londrina: UEL, 2013. Disponível em:

<http://www.uel.br/eventos/congressomultidisciplinar/pages/arquivos/anais/2013/AT01 -2013/AT01-055.pdf>. Acesso em: 15 jun. 2016.

MANZINI, E. J. Entrevista semiestruturada: análise de objetivos e de roteiros. In: SEMINÁRIO INTERNACIONAL SOBRE PESQUISA E ESTUDOS QUALITATIVOS: A PESQUISA QUALITATIVA EM DEBATE, 2., 2004. Bauru. Anais... Bauru: USC, 2004. 1 CD.

REILY, L. As imagens: o lúdico e o absurdo no ensino de arte para pré-escolares surdos. In: SILVA, I. R.; KAUCHAKJE, S.; GESUELI, Z. M. (Org.). Cidadania, surdez e linguagem: desafios e atualidades. São Paulo: Plexus, 2003. p.161-192.

SÁ, N. R. L. de. Questões a propósito de uma avaliação interativa na educação especial e na educação de surdos. Dialógica, Manaus, v. 1, p. 1-11, 2009.

SKLIAR, C. A universidade e a formação de professores, surdos e ouvintes, para uma nova educação de surdos. In: Seminário Pesquisa em Educação Região Sul, 3., 2000, Porto Alegre. Resumo... Porto Alegre: [UFRGS], [200-]. Disponível em: <http://www.portalanpedsul.com.br/admin/uploads/2000/Gestao_e_Politicas/Mesa_Red onda_-_Trabalho/01_46_56_4M3401.pdf>. Acesso em: 15 jun. 2016.

SKLIAR, C. A localização política da educação bilíngue para surdos. In: SKLIAR, C. (Org.). Atualidade da educação bilíngue para surdos: processos e projetos pedagógicos. Porto Alegre: Mediação, 1999. v. 1. p.7-14.

SKLIAR, C. (Org.). Educação e exclusão: abordagens sócio-antropológicas em educação especial. Porto Alegre: Mediação, 1997.

VILELAS, J. Investigação: o processo de construção do conhecimento. Lisboa: Edições Sílabo, 2009.

VYGOTSKY, L. Fundamentos de defectología. Ciudad de La Habana: Pueblo y Educación, 1989. (Obras Completas; tomo V). 